\title{
Serum magnesium and cardiovascular mortality in peritoneal dialysis patients: a 5-year prospective cohort study
}

\author{
Hongjian Ye $\mathrm{Y}^{1,2}$, Peiyi Cao ${ }^{1,2}$, Xiaodan Zhang ${ }^{1,2}$, Jianxiong $\operatorname{Lin}^{1,2}$, Qunying Guo ${ }^{1,2}$, Haiping Mao ${ }^{1,2}$, \\ Xueqing $\mathrm{Yu}^{1,3}$ and Xiao Yang $^{1,2 *}$ \\ ${ }^{1}$ Department of Nephrology, The First Affiliated Hospital, Sun Yat-sen University, 58th, Zhongshan Road II, Guangzhou \\ 510080, People's Republic of China \\ ${ }^{2}$ Key Laboratory of Nephrology, Ministry of Health and Guangdong Province, Guangzhou, Guangdong 510080, \\ People's Republic of China \\ ${ }^{3}$ Guangdong Medical University, Zhanjiang, Guangdong 524023, People's Republic of China \\ (Submitted 19 December 2017 - Final revision received 15 May 2018 - Accepted 22 May 2018 - First published online 19 July 2018)
}

\section{Abstract}

The aim of this study was to explore the association between serum Mg and cardiovascular mortality in the peritoneal dialysis (PD) population. This prospective cohort study included prevalent PD patients from a single centre. The primary outcome of this study was cardiovascular mortality. Serum $\mathrm{Mg}$ was assessed at baseline. A total of 402 patients ( $57 \%$ male; mean age $49 \cdot 3 \pm 14.9$ years) were included. After a median of $49 \cdot 9$ months (interquartile range: 25.9-68.3) of follow-up, sixty-two patients (25.4\%) died of CVD. After adjustment for conventional confounders in multivariate Cox regression models, being in the lower quartile for serum $\mathrm{Mg}$ level was independently associated with a higher risk of cardiovascular mortality, with hazards ratios of 2.28 (95\% CI 1.04, 5.01) 1.41 (95\% CI 0.63, 3.16) and 1.62 (95\% CI 0.75, 3.51) for the lowest, second and third quartiles, respectively. A similar trend was observed when all-cause mortality was used as the study endpoint. Further analysis showed that the relationships between lower serum $\mathrm{Mg}$ and higher risk of cardiovascular and all-cause mortality were present only in the female subgroup, and not among male patients. The test for interaction indicated that the associations between lower serum $\mathrm{Mg}$ and cardiovascular and all-cause mortality differed by sex $(P=0.008$ and $P=0.011$, respectively). In conclusion, lower serum $\mathrm{Mg}$ was associated with a higher risk of cardiovascular and all-cause mortality in the PD population, especially among female patients.

Key words: Lower serum magnesium: Peritoneal dialysis: Cardiovascular mortality: Sex differences: Female patients

$\mathrm{Mg}$ is the fourth most abundant cation in the human body. Clinical observational studies have found that $\mathrm{Mg}$ deficiency is involved in various pathological conditions, especially CVD. A meta-analysis of community-based cohorts concluded that both low Mg intake and low serum Mg levels are significant risk factors for CVD events $^{(1)}$. Low serum $\mathrm{Mg}$ has also been associated with vascular calcification in patients with end-stage renal disease (ESRD) ${ }^{(2)}$; a significant association has been found between low serum $\mathrm{Mg}$ and increased cardiovascular risk in both pre-dialysis chronic kidney disease patients and those undergoing dialysis ${ }^{(3-7)}$.

Peritoneal dialysis (PD) is a well-accepted method of homebased renal replacement therapy for ESRD patients. PD removes dissolved body wastes and extra fluid from the patient's blood via the peritoneal cavity by using dialysate exchanges. The reported prevalence of hypomagnesaemia is high in the PD population, mainly because the routinely used commercial peritoneal dialysate contains a low $\mathrm{Mg}$ level of $0.25 \mathrm{~mol} / \mathrm{l}^{(8,9)}$. Although several retrospective studies have shown that low serum $\mathrm{Mg}$ was associated with an increased risk of hospitalisation and all-cause mortality $^{(10,11)}$, the relationship between serum $\mathrm{Mg}$ and cardiovascular mortality in PD patients has not been rigorously studied. In addition, female patients in the general population are more vulnerable to $\mathrm{CVD}^{(12,13)}$. A prospective cohort study reported that higher plasma Mg concentrations and dietary $\mathrm{Mg}$ intake were associated with a lower risk of sudden cardiac death in women ${ }^{(14)}$. However, sex differences in the relationship between serum $\mathrm{Mg}$ and cardiovascular mortality in patients receiving PD have rarely been described. Therefore, the aim of the present study was to explore the association between serum $\mathrm{Mg}$ and cardiovascular mortality, as well as sex differences in this association, in a prospective cohort of the PD population.

\section{Methods}

\section{Patient information}

This prospective cohort study included prevalent patients from our previous cross-sectional study ${ }^{(8)}$, which was primarily

Abbreviations: ESRD, end-stage renal disease; HR, hazards ratio; IQR, interquartile range; PD, peritoneal dialysis.

* Corresponding author: X. Yang, fax +86 20 87769673, email yangxsysu@126.com 
designed to explore the prevalence and associated factors of hypomagnesaemia at a single centre. Enrolled patients had received PD treatment for more than 1 month and were regularly followed up from February to June 2011. Tenckhoff catheters were placed with sterile surgical technique in all patients. Patients and their caregivers received standardised training after catheterisation. A low-Mg dextrose peritoneal dialysate (containing $\mathrm{Mg}^{2+} 0.25 \mathrm{mmol} / 1, \mathrm{Ca}^{2+} 1.25 \mathrm{mmol} / 1$ or $1.77 \mathrm{mmol} / \mathrm{l}$ ) was used for dialysis. This study was conducted according to the guidelines laid down in the Declaration of Helsinki and all procedures involving patients were approved by the Ethics Committee of The First Affiliated Hospital, Sun Yat-sen University. Written informed consent was obtained from all participants at enrolment.

\section{Demographic and biochemical data}

Demographic and clinical characteristics, including age, sex, primary renal disease, comorbidity conditions, PD duration, daily PD exchange volume, ultrafiltration volume and urine output, as well as history of CVD, which included cerebrovascular disease, IHD, congestive heart failure and peripheral vascular disease at enrolment, were reviewed. Biochemical data, including serum albumin, serum $\mathrm{Mg}$, high-sensitivity C-reactive protein, serum lipid profile, serum $\mathrm{Ca}$, serum $\mathrm{P}$, serum $\mathrm{K}$, intact parathyroid hormone, serum creatinine and blood urea $\mathrm{N}$, were collected at enrolment. All biochemical data were determined with an automatic chemistry analyser (Hitachi 7180 (Boehringer Mannheim) or Abbott Aeroset (Abbott Laboratories)). The serum Mg level was determined with the xylidyl blue method; the normal reference range in this study was $0 \cdot 70-1 \cdot 10 \mathrm{mmol} / \mathrm{l}$. Hypomagnesaemia was defined as a serum Mg level $<0.7 \mathrm{mmol} / \mathrm{l}$. Parameters for adequacy of PD, including the total $\mathrm{Kt} / \mathrm{V}$, weekly creatinine clearance and residual renal function, were also assessed at enrolment according to standard methods ${ }^{(15,16)}$. The normalised protein equivalent of $\mathrm{N}$ appearance was calculated with the modified Bergstrom formula ${ }^{(17)}$, and normalised according to ideal body weight.

\section{Follow-up and study endpoints}

All patients were followed up to the study endpoint, administrative censoring (including renal transplantation, switch to haemodialysis, transfer to another PD centre, loss to follow-up or withdrawal from treatment) or the end of the study follow-up period (31 December 2016). The primary study endpoint was cardiovascular mortality. The secondary endpoint was all-cause mortality. cardiovascular death was defined as death due to IHD, arrhythmia, cardiac sudden death, congestive heart failure, other heart disease or cerebrovascular events ${ }^{(18,19)}$. The PD team consisted of three nephrologists at our centre who reviewed the details of individual medical records and identified the causes of death. If a death had two or more potential causes, we generally ascribed the death to the primary cause for hospitalisation or the initial presenting condition.

\section{Statistical analysis}

Results were expressed as frequencies and percentages for categorical variables, means and standard deviations for continuous variables and medians and interquartile ranges (IQR) for skewed distributions. Baseline serum Mg was evaluated as a continuous variable; values were categorised as hypomagnesaemia or control group, and also into quartiles: quartile $1(\leq 0.66 \mathrm{mmol} / \mathrm{l})$, quartile $2(0.67-0.73 \mathrm{mmol} / \mathrm{l})$, quartile $3(0.74-0.79 \mathrm{mmol} / \mathrm{l})$ and quartile $4(\geq 0.80 \mathrm{mmol} / \mathrm{l})$. To compare sex differences in hypomagnesaemia, patients were divided into four groups (Group 1: females with hypomagnesaemia; Group 2: females without hypomagnesaemia; Group 3: males with hypomagnesaemia; Group 4: males without hypomagnesaemia). For comparisons among these groups, $\chi^{2}$ tests and one-way ANOVA tests or Kruskal-Wallis tests were used to evaluate categorical variables and continuous variables, respectively.

The cumulative risks for all-cause and cardiovascular mortality were evaluated with the Kaplan-Meier method. The associations between serum Mg and outcomes were assessed with Cox proportional hazards regression models. Multivariate models were adjusted for conventional confounding factors and for confounders that have been identified as risk factors related to cardiovascular and all-cause mortality in dialysis patients. The interactions between sex and serum $\mathrm{Mg}$ in the associations with mortality were checked with the Cox regression model. Competing-risks regression models were used to examine the associations between serum $\mathrm{Mg}$ and cardiovascular mortality. In these models, cardiovascular deaths were considered principal, whereas other causes of death were considered competing events.

Calculations were performed with statistical software SPSS (version 19.0; SPSS Inc. and IBM Inc.); the competing risk models were performed with the cmprsk package for $\mathrm{R}$ statistical software. $P$ values of $<0.05$ were considered significant.

\section{Results}

\section{Baseline clinical data}

A total of 402 continuous ambulatory PD patients were enrolled in this study. The mean age of participants was 49.3 (SD 14.9) years, $57 \%$ were male, and the median PD duration at enrolment was 23.3 months (IQR: 11.9-38.1). The leading cause of ESRD was glomerulonephritis ( $59.7 \%$ ), followed by diabetic nephropathy (19.4\%). At enrolment, median daily urine volume was $500 \mathrm{ml} / \mathrm{d}$ (IQR: 100-900). The baseline serum Mg level was $0 \cdot 73$ (sD $0 \cdot 11) \mathrm{mmol} / \mathrm{l}$ (IQR: 0.66-0.79). According to the reference range, $163(40.5 \%)$ patients had hypomagnesaemia. Normality testing of the distribution of serum $\mathrm{Mg}$ in the overall study population indicated non-normal distribution $(P<0 \cdot 001$; Fig. 1). Stratification of the distribution according to sex is shown in Fig. 2.

\section{Comparisons of clinical characteristics stratified according to hypomagnesaemia and sex subgroups}

Patients were divided into four groups according to sex and the presence of hypomagnesaemia (Group 1: females with hypomagnesaemia; Group 2: females without hypomagnesaemia; Group 3: males with hypomagnesaemia; Group 4: males without hypomagnesaemia). Compared with the other three groups, 
female patients with hypomagnesaemia (Group 1) had a shorter time of PD treatment at enrolment $(P<0.001)$; lower daily exchange volume $(P=0.001)$; lower serum $\mathrm{Ca}(P=0.005)$, albumin $(P<0.001), \mathrm{K}(P<0.001)$, phosphate $(P<0.001)$, urea $\mathrm{N}(P<0.001)$ and creatinine $(P=0.003)$; and higher total cholesterol $(P<0 \cdot 001)$ and total Kt/V $(P<0 \cdot 001$; Table 1$)$.

\section{Serum magnesium and cardiovascular and all-cause mortality}

During a median of 49.9 months (IQR: 25.9-68.3) of follow-up, $104(25.8 \%)$ of the 402 patients died, $72(17.9 \%)$ were transferred to haemodialysis, $66(16.4 \%)$ received renal transplantation and $150(37.3 \%)$ remained on PD. Among the deaths, 62 $(59 \cdot 6 \%)$ resulted from CVD, $23(22 \cdot 1 \%)$ from infection, five $(4.8 \%)$ from malignancy, five $(4.8 \%)$ from cachexia and nine $(8.7 \%)$ from other causes.

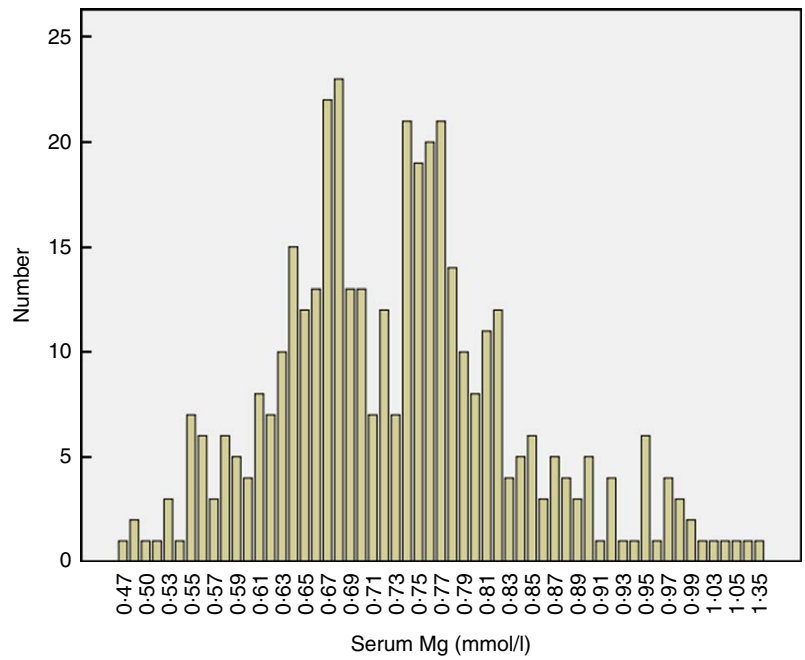

Fig. 1. Distribution of baseline serum magnesium in the study population $\left(P_{\text {for normality test }}<0.001\right)$. Hypomagnesaemia is defined as a serum magnesium level $<0.7 \mathrm{mmol} / \mathrm{l}$.

(a)

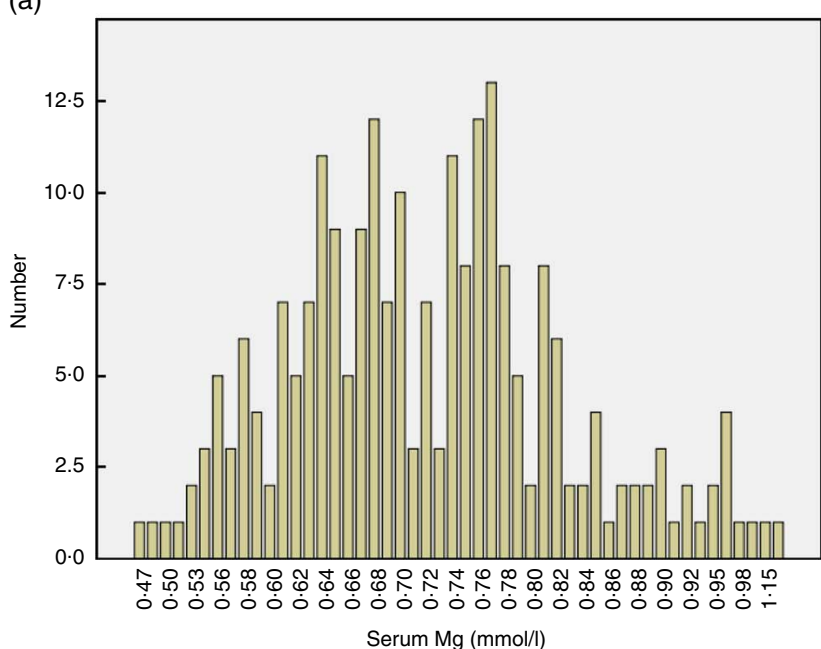

Kaplan-Meier survival analysis revealed a trend that patients with hypomagnesaemia or in the lowest quartile of serum $\mathrm{Mg}$ level had a higher risk for cardiovascular mortality than other patients. However, this trend did not reach statistical significance (Fig. 3). The univariate Cox regression model showed no significant association between serum $\mathrm{Mg}$ and cardiovascular or allcause mortality (Table 2). After adjustment for the conventional confounders, the lower quartile of serum Mg level was independently associated with an increased risk of cardiovascular mortality, with hazards ratios (HR) of 2.28 (95\% CI1.04, 5.01), 1.41 (95\% CI $0.63,3.16)$ and $1.62(95 \%$ CI $0.75,3.51)$ for the lowest, second and third quartiles, respectively. A similar trend was observed when all-cause mortality was considered as the study endpoint (Table 2).

\section{Sex differences in associations between serum magnesium and mortality}

The test for interactions indicated that the associations of hypomagnesaemia with cardiovascular and all-cause mortality differed according to sex $(P=0.008$ and $P=0.011$, respectively; Table 3$)$. We further analysed the relationships between serum $\mathrm{Mg}$ and mortality according to sex. According to Kaplan-Meier survival analysis, hypomagnesaemia was associated with a significantly increased risk for all-cause and cardiovascular mortality in female patients, but not in male patients (Fig. 4). After adjustment for confounders in the multivariate Cox models, lower serum $\mathrm{Mg}$ (HR: 0.58; 95\% CI 0.43, 0.78) and hypomagnesaemia (HR: 2.89; $95 \%$ CI $1.58,5 \cdot 28)$ were independently associated with a higher risk of cardiovascular mortality only in the female subgroup. The risk of cardiovascular mortality was more than three times higher in quartile 1 for serum $\mathrm{Mg}$ than in quartile 4 (HR: 4.16; $95 \%$ CI $1.72,10 \cdot 07)$. Similar results were also observed when all-cause mortality was considered as the study endpoint (Table 3 ).

Considering the potential competing effects of other causes of death on cardiovascular mortality, competing-risks regression models were used to examine the associations between serum

(b)

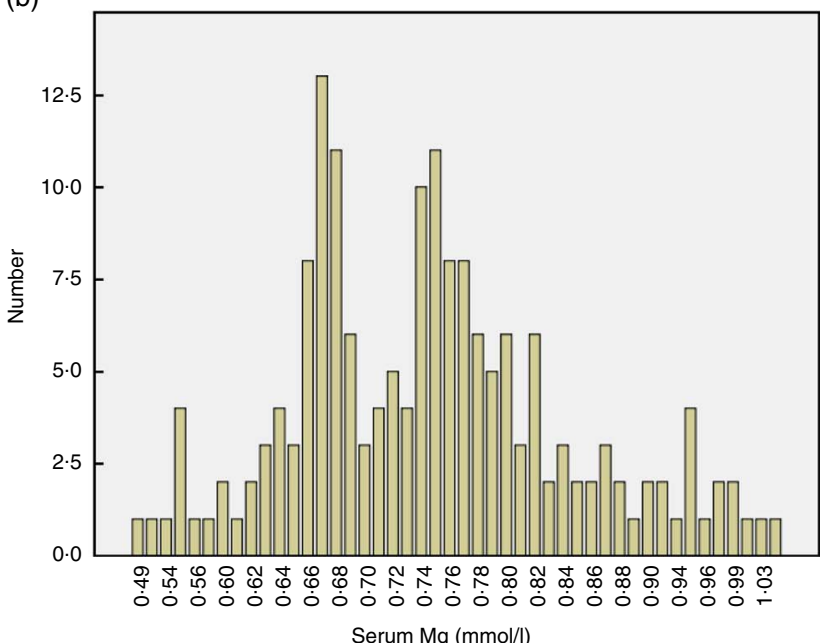

Fig. 2. Stratification of the distribution of baseline serum magnesium according to sex: (a) male and (b) female. 
Table 1. Comparisons of clinical characteristics stratified according to hypomagnesaemia and sex subgroups* (Mean values and standard deviations; medians and interquartile ranges (IQR); percentages)

\begin{tabular}{|c|c|c|c|c|c|c|c|c|c|}
\hline \multirow[b]{3}{*}{ Variables } & \multicolumn{4}{|c|}{ Female } & \multicolumn{4}{|c|}{ Male } & \multirow[b]{3}{*}{$P$} \\
\hline & \multicolumn{2}{|c|}{ Group 1 ( $n$ 62) } & \multicolumn{2}{|c|}{ Group 2 ( $n$ 111) } & \multicolumn{2}{|c|}{ Group 3 ( $n$ 101) } & \multicolumn{2}{|c|}{ Group 4 ( $n$ 128) } & \\
\hline & Mean & $\mathrm{SD}$ & Mean & SD & Mean & SD & Mean & SD & \\
\hline Age (years) & $52 \cdot 1$ & $15 \cdot 9$ & 52.0 & 14.9 & $47 \cdot 8$ & 14.8 & $46 \cdot 9$ & 14.0 & 0.023 \\
\hline Duration of PD at enrolment (months) & & & & & & & & & $<0.001$ \\
\hline Median & \multicolumn{2}{|c|}{$20 \cdot 3$} & \multicolumn{2}{|c|}{28.6} & \multicolumn{2}{|c|}{$15 \cdot 2$} & \multicolumn{2}{|c|}{$26 \cdot 6$} & \\
\hline IQR & \multicolumn{2}{|c|}{$8 \cdot 2-38 \cdot 8$} & \multicolumn{2}{|c|}{$13 \cdot 8-39 \cdot 7$} & \multicolumn{2}{|c|}{$7 \cdot 0-25 \cdot 4$} & \multicolumn{2}{|c|}{$14 \cdot 3-40 \cdot 0$} & \\
\hline Diabetes mellitus (\%) & \multicolumn{2}{|c|}{$17 \cdot 7$} & \multicolumn{2}{|c|}{$20 \cdot 7$} & \multicolumn{2}{|c|}{$20 \cdot 8$} & \multicolumn{2}{|c|}{21.9} & 0.932 \\
\hline Hypertension (\%) & \multicolumn{2}{|c|}{$75 \cdot 8$} & \multicolumn{2}{|c|}{$75 \cdot 7$} & & & & & 0.061 \\
\hline History of CVD (\%) & & & & & & & & & 0.500 \\
\hline History of cardiac arrthymia (\%) & & & & & & & & & 0.199 \\
\hline History of Q-T interval prolongation (\%) & & & & & & & & & 0.616 \\
\hline Daily exchange volume (litres/d) & 7.7 & 1.2 & $7 \cdot 6$ & 1.1 & $8 \cdot 1$ & 1.3 & 8.2 & 1.3 & 0.001 \\
\hline Use of vitamin $D_{3}(\%)$ & & & & & & & & & 0.275 \\
\hline Use of hypertonic dialysate (\%) & & & & & & & & & 0.040 \\
\hline BMI $\left(\mathrm{kg} / \mathrm{m}^{2}\right)$ & 21.4 & 3.1 & $22 \cdot 2$ & $3 \cdot 1$ & $22 \cdot 4$ & $2 \cdot 6$ & $22 \cdot 8$ & 2.9 & 0.029 \\
\hline Ultrafiltration volume $(\mathrm{ml} / \mathrm{d})$ & & & & & & & & & 0.005 \\
\hline Median & & & & & & & & & \\
\hline IQR & 20 & 885 & & & & & & & \\
\hline Urine volume $(\mathrm{ml} / \mathrm{d})$ & & & & & & & & & 0.089 \\
\hline Median & & & & & & & & & \\
\hline IQR & & 750 & & & 225 & 000 & & & \\
\hline Serum $\mathrm{Mg}(\mathrm{mmol} / \mathrm{l})$ & 0.64 & 0.05 & 0.81 & 0.08 & 0.63 & 0.05 & 0.80 & 0.09 & $<0.001$ \\
\hline Serum total $\mathrm{Ca}(\mathrm{mmol} / \mathrm{l})$ & $2 \cdot 36$ & 0.21 & $2 \cdot 38$ & 0.18 & $2 \cdot 29$ & $0 \cdot 17$ & $2 \cdot 33$ & 0.19 & 0.005 \\
\hline Serum phosphate $(\mathrm{mmol} / \mathrm{l})$ & 1.44 & 0.46 & 1.71 & 0.40 & 1.47 & 0.43 & 1.79 & 0.51 & $<0.001$ \\
\hline Serum K (mmol/l) & 3.7 & 0.52 & $4 \cdot 1$ & 0.69 & $4 \cdot 0$ & 0.71 & 4.2 & 0.69 & $<0.001$ \\
\hline Intact parathyroid hormone $(\mathrm{pg} / \mathrm{ml})$ & & & & & & & & & 0.024 \\
\hline Median & & & & & & & & & \\
\hline IQR & & 565 & & & & & & & \\
\hline Serum total protein $(g / l)$ & $65 \cdot 1$ & 7.5 & 68.0 & $6 \cdot 0$ & $64 \cdot 0$ & $6 \cdot 6$ & $65 \cdot 8$ & $6 \cdot 3$ & $<0.001$ \\
\hline Serum albumin $(g / l)$ & 37.9 & $4 \cdot 2$ & 40.0 & $3 \cdot 3$ & 37.9 & $4 \cdot 7$ & $39 \cdot 0$ & 3.9 & $<0.001$ \\
\hline Blood urea $\mathrm{N}(\mathrm{mmol} / \mathrm{l})$ & $16 \cdot 0$ & 3.8 & $18 \cdot 8$ & 4.6 & $18 \cdot 7$ & $5 \cdot 8$ & $20 \cdot 7$ & $5 \cdot 7$ & $<0.001$ \\
\hline Serum creatinine $(\mu \mathrm{mol} / \mathrm{l})$ & 787 & 227 & 902 & 250 & 988 & 340 & 1101 & 355 & $<0.001$ \\
\hline Total cholesterol (mmol/l) & 5.6 & 1.4 & $5 \cdot 6$ & $1 \cdot 2$ & 4.8 & 1.0 & 4.9 & $1 \cdot 1$ & $<0.001$ \\
\hline Hs-CRP (mg/l) & & & & & & & & & 0.875 \\
\hline Median & & & & & & & & & \\
\hline IQR & & & & & & & & & \\
\hline Total Kt/v & 2.5 & 0.5 & 2.4 & 0.7 & $2 \cdot 1$ & 0.7 & $2 \cdot 1$ & 0.7 & $<0.001$ \\
\hline Residual renal function (ml/min per $1.73 \mathrm{~m}^{2}$ ) & & & & & & & & & 0.071 \\
\hline Median & & & & & & & & & \\
\hline IQR & & & & & & & & & \\
\hline nPNA (g/kg per d) & 0.95 & 0.22 & 1.01 & 0.21 & 0.93 & 0.20 & 0.99 & 0.25 & 0.085 \\
\hline Creatinine clearance (litres/week per $1.73 \mathrm{~m}^{2}$ ) & & & & & & & & & 0.157 \\
\hline Median & & & & & & & & & \\
\hline IQR & $52 \cdot 3$ & $30 \cdot 2$ & & $6 \cdot 4$ & 53 & 5.0 & $50 \cdot($ & 0.1 & \\
\hline
\end{tabular}

$\mathrm{PD}$, peritoneal dialysis; Hs-CRP, high-sensitivity C-reactive protein; $\mathrm{nPNA}$, normalised protein equivalent of $\mathrm{N}$ appearance.

* Group 1: female with hypomagnesaemia; Group 2: female without hypomagnesaemia; Group 3: male with hypomagnesaemia; Group 4: male without hypomagnesaemia.

$\mathrm{Mg}$ and cardiovascular mortality. The results from both models give the same message (online Supplementary Tables S1-S3).

\section{Discussion}

Large prospective cohort studies on the relationships between serum $\mathrm{Mg}$ and cardiovascular and all-cause mortality are lacking in the PD population. In this prospective cohort study that included $402 \mathrm{PD}$ patients followed for up to 5 years, we found that a lower serum Mg was independently associated with a higher risk of cardiovascular and all-cause mortality. Further analysis revealed that the negative effects of lower $\mathrm{Mg}$ on mortality were only observed in female patients.
CVD is the leading cause of death in ESRD patients ${ }^{(20)}$. In addition to the traditional factors, there are numerous other CVD risk factors in ESRD patients, such as inflammation, oxidative stress, malnutrition and vascular calcification ${ }^{(21)}$. Close associations between low serum $\mathrm{Mg}$ and an increased risk of CVD or cardiovascular mortality have been observed both among pre-dialysis chronic kidney disease patients and those undergoing haemodialysis ${ }^{(3,5,6)}$. However, the relationship between serum Mg and CVD has not been fully investigated in the PD population. Yang et al. ${ }^{10}$ reported that lower serum Mg levels were associated with an increased risk of hospitalisation and all-cause mortality in a large cohort of incident PD patients in the USA; however, cardiovascular mortality was not discussed in that study. Another retrospective cohort study of PD 
(a)

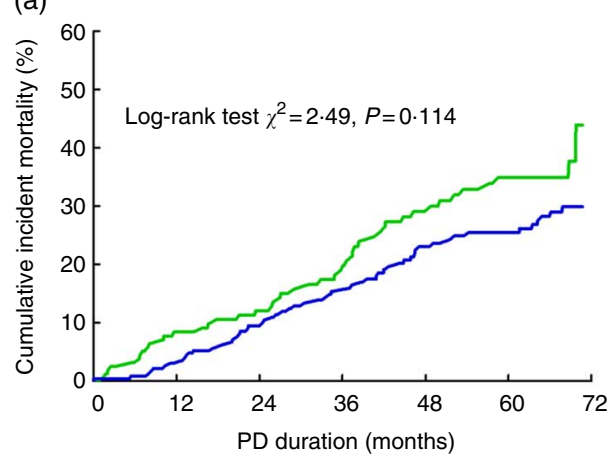

(c)

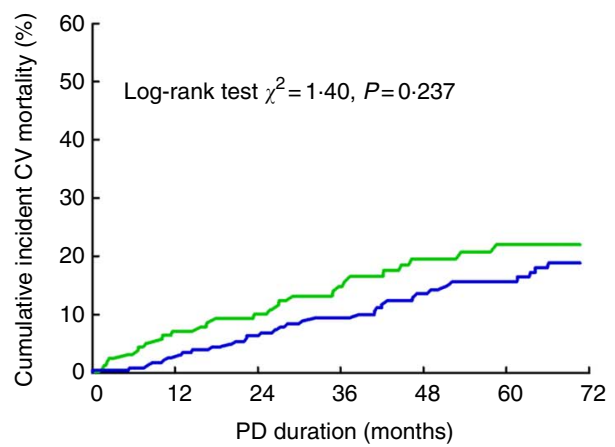

(b)

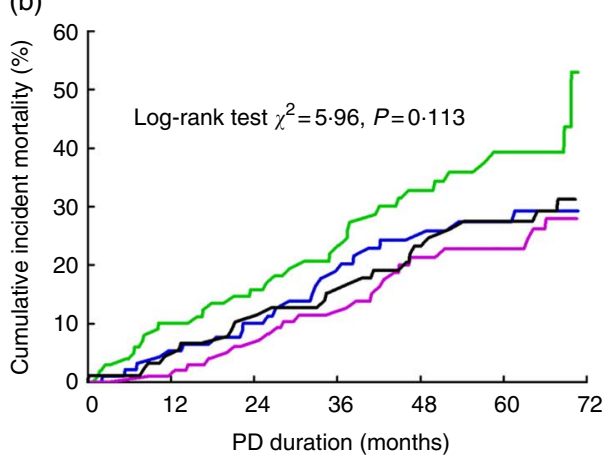

(d)

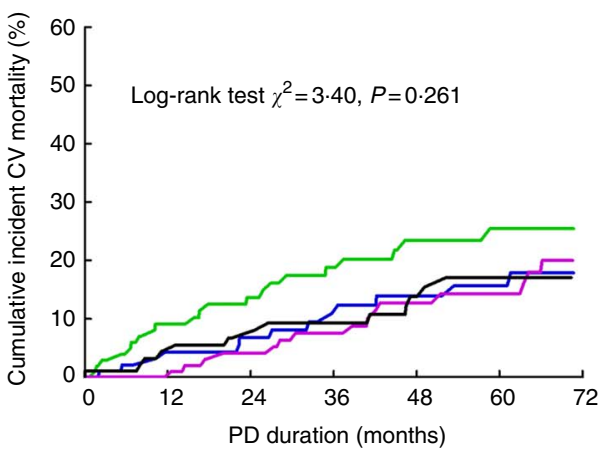

Fig. 3. Serum magnesium and mortality in peritoneal dialysis (PD) patients. Cumulative risk for all-cause mortality in the entire patients stratified by hypomagnesaemia (a) and magnesium quartiles (b); cumulative risk for cardiovascular (CV) mortality in the entire patients stratified by hypomagnesaemia (c) and magnesium quartiles (d). $(\mathrm{a}, \mathrm{c}):-$, Hypomagnesaemia group; - , control group. $(\mathrm{b}, \mathrm{d}):-{ }_{-}$, Quartile $1 ;-$, quartile $2 ;-$, quartile $3 ;-$, quartile 4.

Table 2. Associations between serum magnesium and mortality in the Cox regression models*

(Hazard ratios (HR) and $95 \%$ confidence intervals)

\begin{tabular}{|c|c|c|c|c|c|c|}
\hline \multirow[b]{2}{*}{ Variables } & \multicolumn{3}{|c|}{ Model 1} & \multicolumn{3}{|c|}{ Model 2} \\
\hline & $\mathrm{HR}$ & $95 \% \mathrm{Cl}$ & $P$ & $\mathrm{HR}$ & $95 \% \mathrm{Cl}$ & $P$ \\
\hline \multicolumn{7}{|l|}{ Cardiovascular mortality } \\
\hline Continuous Mg† & 0.85 & $0.67,1.08$ & 0.174 & 0.82 & $0.64,1.06$ & 0.131 \\
\hline $\begin{array}{l}\text { Hypomagnesaemia } \\
\text { (yes } v \text {. no) }\end{array}$ & 1.35 & $0.82,2 \cdot 23$ & 0.239 & 1.43 & $0.80,2.56$ & 0.230 \\
\hline \multicolumn{7}{|l|}{ Mg quartiles } \\
\hline Quartile 1 & 1.73 & $0.87,3.46$ & 0.120 & $2 \cdot 28$ & $1 \cdot 04,5 \cdot 01$ & 0.041 \\
\hline Quartile 2 & 1.03 & $0.48,2.23$ & 0.931 & 1.41 & $0.63,3.16$ & 0.408 \\
\hline Quartile 3 & 1.02 & $0.49,2 \cdot 15$ & 0.956 & 1.62 & $0.75,3.51$ & 0.218 \\
\hline Quartile 4 & 1.00 & Ref. & - & 1.00 & Ref. & - \\
\hline $\begin{array}{l}P_{\text {for trend }} \\
\text { All-cause mortality }\end{array}$ & \multicolumn{2}{|c|}{0.113} & - & \multicolumn{2}{|c|}{0.045} & - \\
\hline Continuous Mg† & 0.85 & $0.71,1.02$ & 0.088 & 0.83 & $0.68,1.01$ & 0.058 \\
\hline $\begin{array}{l}\text { Hypomagnesaemia } \\
\text { (yes } v \text {. no) }\end{array}$ & 1.36 & $0.93,2.01$ & 0.116 & 1.53 & $0.98,2.39$ & 0.063 \\
\hline \multicolumn{7}{|l|}{ Mg quartiles } \\
\hline Quartile 1 & 1.55 & $0.92,2.61$ & 0.102 & 1.89 & $1.04,3.42$ & 0.037 \\
\hline Quartile 2 & 1.00 & $0.56,1.78$ & 0.988 & 1.46 & $0.80,2.65$ & 0.217 \\
\hline Quartile 3 & 0.85 & $0.48,1.51$ & 0.588 & $1 \cdot 20$ & $0 \cdot 66,2 \cdot 18$ & 0.561 \\
\hline Quartile 4 & 1.00 & Ref. & - & 1.00 & Ref. & - \\
\hline$P_{\text {for trend }}$ & \multicolumn{2}{|c|}{0.070} & - & \multicolumn{2}{|r|}{0.030} & - \\
\hline
\end{tabular}

Ref., referent values.

* Model 1: univariate analysis; model 2: adjusted for age, sex, hypertension, diabetes, history of CVD, peritoneal dialysis duration at enrolment, serum phosphate and urine volume. Mg concentrations for quartiles: quartile $1(\leq 0.66 \mathrm{mmol} / \mathrm{l})$, quartile 2 $(0.67-0.73 \mathrm{mmol} / \mathrm{l})$, quartile $3(0.74-0.79 \mathrm{mmol} / \mathrm{l})$ and quartile $4(\geq 0.80 \mathrm{mmol} / \mathrm{l})$.

† Per $0.1 \mathrm{mmol} / \mathrm{l}$ increase of $\mathrm{Mg}$. patients reported that serum $\mathrm{Mg}$ was an independent negative predictor of all-cause and cardiovascular mortality ${ }^{(11)}$; however, that study included only thirty-six patients with hypomagnesaemia and the multivariate models did not adjust for a history of CVD, both of which may have affected the results. In the current prospective cohort study, we included a larger sample size of PD patients and demonstrated that lower serum Mg may increase the risk of cardiovascular and all-cause mortality, providing further evidence for the close relationship.

The underlying mechanisms for the association between serum $\mathrm{Mg}$ and CVD remain unclear; several potential mechanisms may be involved. First, hypomagnesaemia has been linked with increased comorbidity and cardiovascular risk factors ${ }^{(5)}$, including C-reactive protein, atherosclerosis, hypertension and dyslipidaemia, which are important for the development of CVD. Second, low serum Mg in PD patients may be associated with vascular calcification $^{(2)}$, which is a significant pathophysiological cause of CVD. In a mouse model of pseudoxanthoma elasticum, Mg supplementation reduced carotid intima-media thickness, probably by inhibiting hydroxyapatite formation and increasing natural inhibitors of calcification ${ }^{(22,23)}$. In clinical observation, close associations have also been described between low serum $\mathrm{Mg}$ and vascular calcification in haemodialysis and PD patients ${ }^{(2,24)}$. Third, Mg is recognised as a regulatory factor in endothelial dysfunction. In an animal model, deficiency of dietary $\mathrm{Mg}$ was found to induce endothelial dysfunction ${ }^{(25)}$, whereas oral $\mathrm{Mg}$ supplementation improved endothelial dysfunction in patients 
Table 3. Interaction tests of hypomagnesaemia and sex and mortality, and the sexual difference in the associations between magnesium and mortality* (Hazard ratios (HR) and $95 \%$ confidence intervals)

\begin{tabular}{|c|c|c|c|c|c|c|}
\hline \multirow[b]{2}{*}{ Variables } & \multicolumn{3}{|c|}{ Cardiovascular mortality } & \multicolumn{3}{|c|}{ All-cause mortality } \\
\hline & HR & $95 \% \mathrm{Cl}$ & $P$ & $\mathrm{HR}$ & $95 \% \mathrm{Cl}$ & $P$ \\
\hline \multicolumn{7}{|c|}{ Interaction tests for mortality in entire cohort ( $n$ 402, cardiovascular deaths $=62$, all-cause deaths $=104$ ) } \\
\hline $\begin{array}{l}\text { Hypomagnesaemia (yes v. no) } \\
\text { Sex (female/male) } \\
\text { Hypomagnesaemia × sex }\end{array}$ & \multicolumn{3}{|c|}{$P_{\text {for interaction }}=0.008$} & \multicolumn{3}{|c|}{$P_{\text {for interaction }}=0.011$} \\
\hline Females ( $n$ 173) & \multicolumn{3}{|c|}{ No. of cardiovascular deaths $=30$} & \multicolumn{3}{|c|}{ No. of all-cause deaths $=51$} \\
\hline Continuous Mg† & 0.52 & $0.35,0.78$ & 0.002 & 0.58 & $0.43,0.78$ & $<0.001$ \\
\hline $\begin{array}{l}\text { Hypomagnesaemia (yes } v . \text { no) } \\
\text { Mg quartiles }\end{array}$ & \multicolumn{5}{|c|}{ Mg quartiles } & 0.001 \\
\hline Quartile 1 & 4.56 & $1.49,13.96$ & 0.008 & $4 \cdot 16$ & $1.72,10.07$ & 0.002 \\
\hline Quartile 2 & 1.51 & $0.44,5.16$ & 0.509 & 2.26 & $0.90,5.64$ & 0.081 \\
\hline Quartile 3 & 1.27 & $0.38,4.29$ & 0.703 & 1.46 & $0.57,3.69$ & 0.429 \\
\hline Quartile 4 & 1.00 & Ref. & - & 1.00 & Ref. & - \\
\hline$P_{\text {for trend }}$ & \multirow{2}{*}{\multicolumn{3}{|c|}{$\begin{array}{l}0.006 \\
\text { No. of cardiovascular deaths }=32\end{array}$}} & \multirow{2}{*}{\multicolumn{3}{|c|}{$\begin{array}{l}0.001 \\
\text { No. of all-cause deaths }=53\end{array}$}} \\
\hline Males ( $n$ 229) & & & & & & \\
\hline Continuous Mg† & 1.02 & $0.76,1.38$ & 0.875 & 1.05 & $0.83,1.32$ & 0.693 \\
\hline Hypomagnesaemia (yes v. no) & 0.73 & $0.34,1.60$ & 0.436 & 0.84 & $0.46,1.53$ & 0.56 \\
\hline \multicolumn{7}{|l|}{ Mg quartiles } \\
\hline Quartile 1 & 1.41 & $0.48,4 \cdot 11$ & 0.531 & 0.99 & $0.45,2.19$ & 0.980 \\
\hline Quartile 2 & 1.23 & $0.41,3.70$ & 0.718 & 1.01 & $0.44,2.31$ & 0.987 \\
\hline Quartile 3 & 1.97 & $0.71,5.43$ & 0.190 & 1.11 & $0.50,2.50$ & 0.795 \\
\hline Quartile 4 & 1.00 & Ref. & - & 1.00 & Ref. & - \\
\hline$P_{\text {for trend }}$ & \multicolumn{2}{|c|}{0.740} & - & \multicolumn{2}{|c|}{0.934} & - \\
\hline
\end{tabular}

Ref., referent values.

* All the models were adjusted for age, diabetes, hypertension, history of CVD, PD duration at enrolment, serum phosphate and urine volume in the COX regression models; Mg concentrations for quartiles: quartile $1(\leq 0.66 \mathrm{mmol} / \mathrm{l})$, quartile $2(0.67-0.73 \mathrm{mmol} / \mathrm{l})$, quartile $3(0.74-0.79 \mathrm{mmol} / \mathrm{l})$ and quartile $4(\geq 0.80 \mathrm{mmol} / \mathrm{l})$.

† Per $0.1 \mathrm{mmol} / \mathrm{l}$ increase of $\mathrm{Mg}$.

(a)

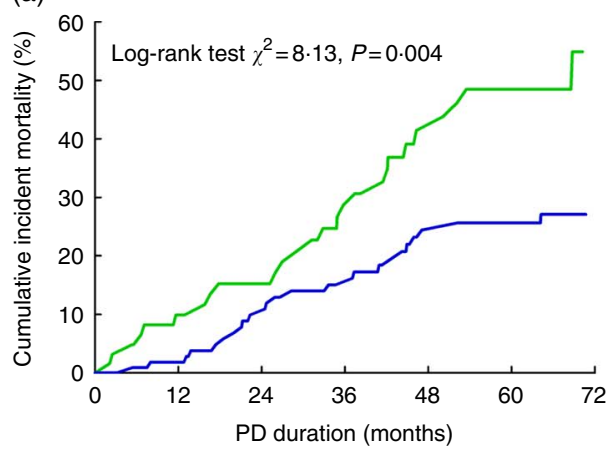

(c)

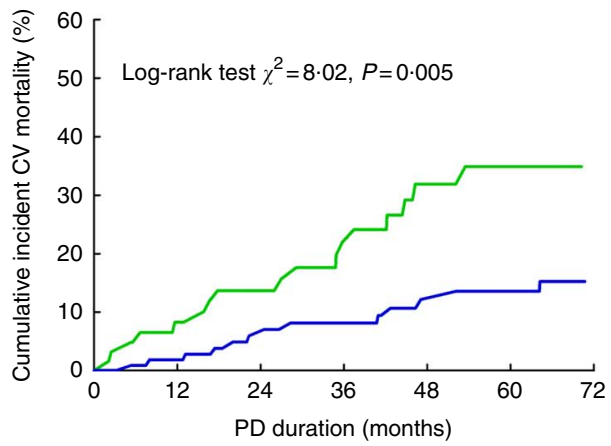

(b)

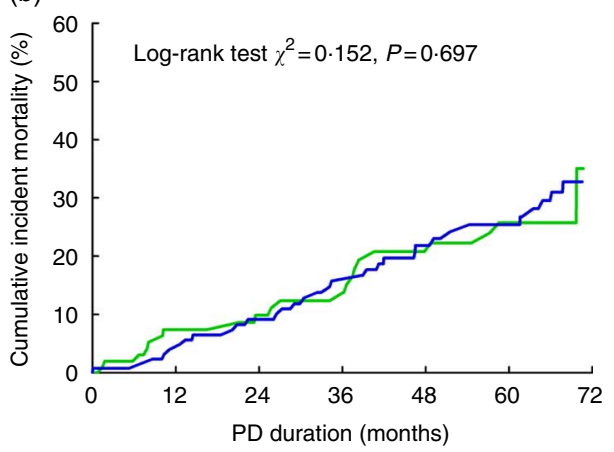

(d)

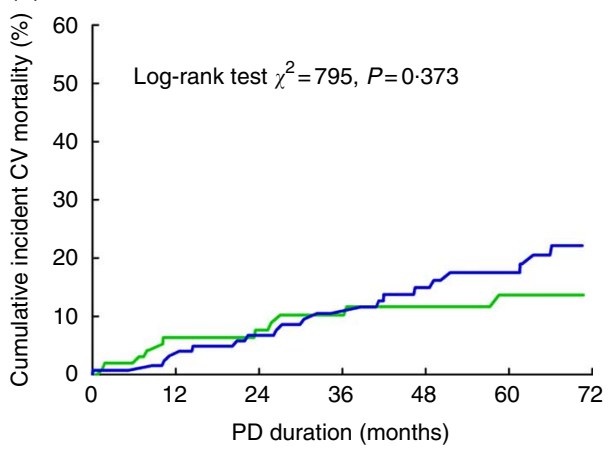

Fig. 4. Hypomagnesaemia and mortality stratified by sex in peritoneal dialysis (PD) patients. Cumulative risk for all-cause mortality in female patients (a) and male patients (b); cumulative risk for cardiovascular (CV) mortality in female patients (c) and male patients (d). — - Hypomagnesaemia group; — 
with coronary artery disease ${ }^{(26)}$. In addition, higher $\mathrm{Mg}$ exposure was shown to halt smooth muscle cell proliferation and stimulate endothelial cell proliferation in vitro ${ }^{(27)}$.

We found that serum Mg was not significantly associated with cardiovascular mortality in univariate analysis, indicating that the effects of serum $\mathrm{Mg}$ on mortality might be influenced by confounders. In addition, interaction analysis indicated that sex was the most important effect modifier in the current study. In subgroup analysis, hypomagnesaemia (HR: $2 \cdot 89 ; 95 \%$ CI $1 \cdot 58,5 \cdot 28$ ) was independently associated with a higher risk of cardiovascular mortality only in the female subgroup, further demonstrating the sex difference. Such sex differences in the association between lower serum $\mathrm{Mg}$ and cardiovascular mortality in the dialysis population have rarely been reported. Chiuve et al. ${ }^{(14)}$ reported that higher plasma $\mathrm{Mg}$ concentrations and dietary $\mathrm{Mg}$ intake were associated with a lower risk of sudden cardiac death in a prospective cohort (Nurses' Health Study) of women without chronic kidney disease. Interestingly, a meta-analysis that included several prospective studies also showed a protective effect of dietary $\mathrm{Mg}$ intake on CVD mortality risk in women but not in men ${ }^{(1)}$. This evidence suggests that cardiac responses to $\mathrm{Mg}$ deficiency may be different in women than in men. However, none of these studies has described a clear underlying mechanism of this phenomenon.

The different pathophysiological conditions of heart disease in women and the adverse cardiac outcomes caused by serum $\mathrm{Mg}$ deficiency may account for the sex-related differences found in this study. Women are more vulnerable than men to $\mathrm{CVD}^{(12,13)}$; women also more often have a longer QTc interval than men ${ }^{(28,29)}$, which is associated with an increased risk of life-threatening cardiac arrhythmias (such as torsade de pointes and polymorphic ventricular tachycardia) and sudden cardiac death $^{(30,31)}$. Severe serum Mg deficiency has been correlated with torsade de pointes and certain ventricular tachycardia events; intravenous $\mathrm{Mg}$ is regarded as the treatment of choice in these cases, even if hypomagnesaemia is not present ${ }^{(32,33)}$. Moreover, the phenomenon that oral $\mathrm{Mg}$ shortens the prolonged QTc interval caused by medications also suggests that Mg may be an important regulator in the electrocardio physiological process ${ }^{(34)}$. As described above, the incidence of hypomagnesaemia is high among PD patients in whom a low$\mathrm{Mg}$ dialysate is routinely used ${ }^{(9,35,36)}$. Taking these factors together, including women's susceptibility to CVD, the close association between serum $\mathrm{Mg}$ and life-threatening cardiac arrhythmias, and the high prevalence of hypomagnesaemia among PD patients, it is not surprising that female PD patients with lower serum $\mathrm{Mg}$ had a higher cardiovascular mortality than other patients.

Another explanation for the relationship between hypomagnesaemia and cardiovascular mortality may be the close association between hypomagnesaemia and poor nutritional status $^{(7,8,37,38)}$. Malnutrition is a strong risk factor for CVD and atherosclerosis in patients with advanced chronic renal failure ${ }^{(39,40)}$. Although malnutrition is rarely the direct cause of cardiac death, it may predispose to reduced cardiac contractility and atherosclerotic vascular disease and may contribute to cardiovascular death by aggravating pre-existing cardiovascular disease $^{(41)}$. In the current study, female patients with hypomagnesaemia also had significantly lower levels of serum albumin, phosphate, urea nitrogen and creatinine than other patients, all of which are regarded as nutritional markers of chronic renal failure ${ }^{(42)}$. Therefore, it is possible that the female PD patients with low serum $\mathrm{Mg}$ had poor nutritional status, which may have contributed to their higher risk of cardiovascular mortality.

The strengths of this study include its large and prospective cohort of patients receiving PD with a follow-up time of up to 5 years and complete data on clinical outcomes. However, our study has several limitations that should be considered. First, the patients enrolled were from a single PD centre and our previous cross-sectional study did not include the entire population of PD patients, inevitably introducing selection bias. Second, we did not collect data on dietary $\mathrm{Mg}$ intake or Mg loss in dialysate and urine; therefore, we cannot perform an in-depth analysis of $\mathrm{Mg}$ metabolism and mortality in this population. In addition, because the current prospective study did not involve any intervention for low serum $\mathrm{Mg}$, we cannot say whether Mg supplementation is beneficial for PD patients. Finally, electrocardiogram data were not collected for most deaths that occurred outside the hospital. Therefore, a direct relationship between hypomagnesaemia and fatal cardiac arrhythmia is difficult to confirm.

\section{Conclusion}

Lower serum Mg was associated with a higher risk of cardiovascular and all-cause mortality in PD patients; however, the impact of lower serum $\mathrm{Mg}$ on mortality was mainly found in female patients. The current results suggest that we should pay close attention to serum Mg in PD patients, especially in female patients. Regular monitoring and supplementation may be helpful for patients with hypomagnesaemia.

\section{Acknowledgements}

The authors thank all nephrologists and nurses in our PD centre for their excellent management of PD patients. Thanks for the kind suggestions for the statistical methodology by Li Fan, MD and Hui Zhang, PhD. The authors thank Rebecca Tollefson, DVM, from Liwen Bianji, Edanz Editing China (www.liwenbianji.cn/ac), for editing the English text of a draft of this manuscript.

This work was supported by the Natural Science Foundation of China (grant nos. 81570614, 81774069), National Key Research and Development program (grant no. 2016YFC0906101), the Guangdong Science Foundation of China (grant nos. 2014A030313139, 2014B020212020, 2017A050503003, 2017B020227006,), Foundation of Guangdong Key Laboratory of Nephrology (grant no. 2014B030301023) and the Guangzhou Committee of Science and Technology, China (grant nos. 2014Y2-00543, 201704020167).

The authors' contributions are as follows: H. Y., X. Yu and $\mathrm{X}$. Yang contributed to the study design, data analyses, interpretation of the findings and wrote the manuscript; P. C., X. Z., J. L., Q. G. and H. M. contributed to the study design, subject briefings and data collection. All authors read and approved the final version of the manuscript.

The authors declare that there are no conflicts of interest. 


\section{Supplementary material}

For supplementary material/s referred to in this article, please visit https://doi.org/10.1017/S0007114518001599

\section{References}

1. Xu T, Sun Y, Xu T, et al. (2013) Magnesium intake and cardiovascular disease mortality: a meta-analysis of prospective cohort studies. Int J Cardiol 167, 3044-3047.

2. Molnar AO, Biyani M, Hammond I, et al. (2017) Lower serum magnesium is associated with vascular calcification in peritoneal dialysis patients: a cross sectional study. BMC Nephrol 18, 129

3. Kanbay M, Yilmaz MI, Apetrii M, et al. (2012) Relationship between serum magnesium levels and cardiovascular events in chronic kidney disease patients. Am J Nephrol 36, 228-237.

4. Sakaguchi Y, Fujii N, Shoji T, et al. (2014) Hypomagnesemia is a significant predictor of cardiovascular and non-cardiovascular mortality in patients undergoing hemodialysis. Kidney Int $\mathbf{8 5}$, 174-181.

5. Joao Matias P, Azevedo A, Laranjinha I, et al. (2014) Lower serum magnesium is associated with cardiovascular risk factors and mortality in haemodialysis patients. Blood Purif $\mathbf{3 8}$, 244-252.

6. Lacson E Jr, Wang W, Ma L, et al. (2015) Serum magnesium and mortality in hemodialysis patients in the United States: a cohort study. Am J Kidney Dis 66, 1056-1066.

7. Markaki A, Kyriazis J, Stylianou K, et al. (2012) The role of serum magnesium and calcium on the association between adiponectin levels and all-cause mortality in end-stage renal disease patients. PLOS ONE 7, e52350.

8. Ye H, Zhang X, Guo Q, et al. (2013) Prevalence and factors associated with hypomagnesemia in Southern Chinese continuous ambulatory peritoneal dialysis patients. Perit Dial Int 33, 450-454.

9. Ejaz AA, McShane AP, Gandhi VC, et al. (1995) Hypomagnesemia in continuous ambulatory peritoneal dialysis patients dialyzed with a low-magnesium peritoneal dialysis solution. Perit Dial Int 15, 61-64.

10. Yang X, Soohoo M, Streja E, et al. (2016) Serum magnesium levels and hospitalization and mortality in incident peritoneal dialysis patients: a cohort study. Am J Kidney Dis 68, 619-627.

11. Cai K, Luo Q, Dai Z, et al. (2016) Hypomagnesemia is associated with increased mortality among peritoneal dialysis patients. PLOS ONE 11, e0152488.

12. Wenger NK (2012) Cardiovascular disease: the female heart is vulnerable: a call to action from the $10 \mathrm{Q}$ report. Clin Cardiol 35, 134-135.

13. Xuereb R, Magri CJ, Xuereb S, et al. (2016) Female gender and cardiovascular disease. Br J Hosp Med (Lond) 77, 454-459.

14. Chiuve SE, Korngold EC, Januzzi JL Jr, et al. (2011) Plasma and dietary magnesium and risk of sudden cardiac death in women. Am J Clin Nutr 93, 253-260.

15. Nolph KD, Moore HL, Twardowski ZJ, et al. (1992) Crosssectional assessment of weekly urea and creatinine clearances in patients on continuous ambulatory peritoneal dialysis. ASAIO J 38, M139-M142.

16. van Olden RW, Krediet RT, Struijk DG, et al. (1996) Measurement of residual renal function in patients treated with continuous ambulatory peritoneal dialysis. J Am Soc Nephrol 7, 745-750.

17. Bergstrom J, Furst P, Alvestrand A, et al. (1993) Protein and energy intake, nitrogen balance and nitrogen losses in patients treated with continuous ambulatory peritoneal dialysis. Kidney Int 44, 1048-1057.

18. Cheung AK, Sarnak MJ, Yan G, et al. (2004) Cardiac diseases in maintenance hemodialysis patients: results of the HEMO Study. Kidney Int 65, 2380-2389.

19. Delmez JA, Yan G, Bailey J, et al. (2006) Cerebrovascular disease in maintenance hemodialysis patients: results of the HEMO Study. Am J Kidney Dis 47, 131-138.

20. de Jager DJ, Grootendorst DC, Jager KJ, et al. (2009) Cardiovascular and noncardiovascular mortality among patients starting dialysis. JAMA 302, 1782-1789.

21. Stenvinkel P, Carrero JJ, Axelsson J, et al. (2008) Emerging biomarkers for evaluating cardiovascular risk in the chronic kidney disease patient: how do new pieces fit into the uremic puzzle? Clin J Am Soc Nephrol 3, 505-521.

22. Kupetsky-Rincon EA, Li Q \& Uitto J (2012) Magnesium reduces carotid intima-media thickness in a mouse model of pseudoxanthoma elasticum: a novel treatment biomarker. Clin Transl Sci 5, 259-264.

23. Kupetsky EA, Rincon F \& Uitto J (2013) Rate of change of carotid intima-media thickness with magnesium administration in Abcc6(-)/(-) mice. Clin Transl Sci 6, 485-486.

24. Ishimura E, Okuno S, Kitatani K, et al. (2007) Significant association between the presence of peripheral vascular calcification and lower serum magnesium in hemodialysis patients. Clin Nephrol 68, 222-227.

25. Maier JA (2012) Endothelial cells and magnesium: implications in atherosclerosis. Clin Sci (Lond) 122, 397-407.

26. Shechter M, Sharir M, Labrador MJ, et al. (2000) Oral magnesium therapy improves endothelial function in patients with coronary artery disease. Circulation 102, 2353-2358.

27. Sternberg K, Gratz M, Koeck K, et al. (2012) Magnesium used in bioabsorbable stents controls smooth muscle cell proliferation and stimulates endothelial cells in vitro. $J$ Biomed Mater Res B Appl Biomater 100, 41-50.

28. Hreiche R, Morissette P \& Turgeon J (2008) Drug-induced long QT syndrome in women: review of current evidence and remaining gaps. Gend Med 5, 124-135.

29. Whang W, Julien HM, Higginbotham L, et al. (2012) Women, but not men, have prolonged QT interval if depressed after an acute coronary syndrome. Europace 14, 267-271.

30. Velat I \& Culic V (2014) Circulating magnesium and cardiovascular events. Am J Clin Nutr 99, 647-648.

31. Straus SM, Kors JA, De Bruin ML, et al. (2006) Prolonged QTc interval and risk of sudden cardiac death in a population of older adults. J Am Coll Cardiol 47, 362-367.

32. Martin KJ, Gonzalez EA \& Slatopolsky E (2009) Clinical consequences and management of hypomagnesemia. J Am Soc Nephrol 20, 2291-2295.

33. Agus ZS (1999) Hypomagnesemia. J Am Soc Nephrol 10, 1616-1622.

34. Bachman DM (2003) Oral magnesium ion shortens prolonged QTc interval. J Clin Psychiatry 64, 733-734.

35. Shah GM, Winer RL, Cutler RE, et al. (1987) Effects of a magnesium-free dialysate on magnesium metabolism during continuous ambulatory peritoneal dialysis. Am J Kidney Dis 10, 268-275.

36. Katopodis KP, Koliousi EL, Andrikos EK, et al. (2003) Magnesium homeostasis in patients undergoing continuous ambulatory peritoneal dialysis: role of the dialysate magnesium concentration. Artif Organs 27, 853-857.

37. Wada T, Hirayama T, Hibino Y, et al. (2014) Malnutrition as cause of hypomagnesemia. Kidney Int $\mathbf{8 6}, 856$.

38. Alhosaini M \& Leehey DJ (2015) Magnesium and dialysis: the neglected cation. Am J Kidney Dis 66, 523-531. 
39. Stenvinkel P, Heimburger O, Paultre F, et al. (1999) Strong association between malnutrition, inflammation, and atherosclerosis in chronic renal failure. Kidney Int 55, 1899-1911.

40. Suliman ME, Qureshi AR, Barany P, et al. (2000) Hyperhomocysteinemia, nutritional status, and cardiovascular disease in hemodialysis patients. Kidney Int 57, 1727-1735.
41. Bergstrom J \& Lindholm B (1998) Malnutrition, cardiac disease, and mortality: an integrated point of view. Am J Kidney Dis 32, 834-841.

42. Anonymous (2000) Clinical practice guidelines for nutrition in chronic renal failure. K/DOQI, National Kidney Foundation. Am J Kidney Dis 35, S1-S140. 